\title{
Modelling Canopy Development, Biomass and Yield of Maize (Zea mays L.) under Optimal Management
}

\author{
J.B.D.A.P. Kumara*, L.D.B. Suriyagoda ${ }^{1}$, W.A.J.M. De Costa ${ }^{1}$ \\ and M.A.P.W.K. Mallaviarachchi ${ }^{2}$
}

Postgraduate Institute of Agriculture

University of Peradeniya

Sri Lanka

\begin{abstract}
Among upland cereals, Maize ( $\underline{\text { Zea mays }}$ L.) is considered as the most important cereal crop in Sri Lanka. Successful expansion of maize cultivation requires knowledge on its yield potential. Conventional agronomic research may require considerable time and physical resources to generate the relevant knowledge whereas simulation modelling would enable prediction of crop responses to varying environment and management conditions with less time and resources. Therefore, the objective of this research was to develop a process-based simulation model to predict the yield potential of maize in different agro-ecological zones of Sri Lanka under recommended crop management. Detailed leaf initiation and expansion data of maize growing at Kundasale $\left(I_{3 a}\right)$ in Sri Lanka under recommended crop management practices were used to construct a canopy development sub-model, which is driven by the thermal responses of leaf initiation and expansion. Time-courses of canopy leaf area index estimated based on the canopy development sub-model were used to estimate radiation interception. Biomass production and yield were estimated from intercepted radiation using radiation-use efficiency and harvest index, respectively. Model predictions were compared with independent data collected from field experiments at Peradeniya $\left(W M_{2 b}\right)$ and Maha-Illuppallama $\left(D L_{1 b}\right)$. Results were in agreement with actual data of leaf initiation, individual leaf area, leaf area index, above ground biomass and yield with respective Root Mean Square Error (RMSE) values being 0.89, 81.13, 0.45, 0.14 and 0.06, respectively. Simulations predicted that increased growing season temperature decreased the number of days to tasseling and crop maturity by 3.1 and 4.1 days per ${ }^{\circ} \mathrm{C}$, respectively, which were in agreement with the observed data.
\end{abstract}

Keywords: Canopy development, ecological gradient, maize, simulation modelling

\section{INTRODUCTION}

Maize (Zea mays L.) is the third major cereal crop in the world after wheat and rice (Lukeba et al., 2013), and the most important highland cereal in Asia (Timsina et al., 2010, Sangakkara et al., 2012). Therefore, in Sri Lanka, among upland cereals, maize has received major attention, and recent government policies and increased profit margins have triggered a two-fold increase in cultivated extent (57,618 ha) and production $(161,694 \mathrm{mt})$ in $2011 \mathrm{in}$ comparison to 2006 (Central Bank Annual Report, 2012). Despite the above increases in

\footnotetext{
Department of Crop Science, Faculty of Agriculture, University of Peradeniya, Sri Lanka

2 Field Crops Research and Development Institute, Mahailluppallama, Sri Lanka

Corresponding author:arunajbd@gmail.com
} 
production, a large quantity of grains is still imported to meet the deficit in the national requirement (Mallaviarachchi et al., 2008). Expansion of cultivation to non conventional areas is one approach to meet the national demand. However, it requires knowledge about the potential of different agro ecological regions to produce maize. One way of filling this knowledge gap is by conducting agronomic experiments in various locations representing different agro ecological regions to determine the yield potential of maize in those respective environments. However, traditional agronomic experiments conducted at particular points in time and space, make the results generated site- and season-specific, time consuming and expensive (Jones et al., 2003). An alternative approach is to use simulation models to predict the yield potential of maize under a given set of environmental and management conditions. A well-calibrated and tested simulation model requires less time and resources to predict the yield potential of a crop under a given set of environmental and management conditions in comparison to a series of multi-locational experiments.

Models are powerful tools to test hypotheses, synthesize knowledge, describe and understand complex systems and compare different scenarios (Marcelis et al., 1998). In agriculture, crop modeling is used to quantify and predict the growth and yield formation processes over the life cycle of a crop and also to predict their responses to variations in environmental and management factors. These processes include phenological progression, organ initiation and expansion, biomass accumulation and partitioning and yield formation. The present paper specifically focuses on modeling leaf growth and canopy development of maize to estimate its leaf area index (LAI), which is a key determinant of radiation interception, biomass accumulation and yield under local conditions (Dwyer \& Stewart 1986, Birch et al., 1998, Setiyono et al., 2007, Lukeba et al., 2013). Moreover, this study is the first step to develop such a model which can be used under Sri Lankan conditions and for local varieties. Outputs from such a model could then be compared with those of models developed elsewhere, which also need to be parameterized for maize varieties grown in Sri Lanka. Therefore, the objectives of the present work are to (1) collect the required data, parameterize and develop a simple model to estimate leaf initiation, canopy expansion, radiation interception and biomass production of inbred maize varieties produced in Sri Lanka and growing under Sri Lankan conditions, and (2) validate the simulation model using data from a multi-locational field experiment.

\section{METHODOLOGY}

Field experiments were conducted at three locations (i.e. Peradeniya, Kundasale and Mahailluppallama) in Sri Lanka. These sites were selected to represent different rainfall and temperature regimes representing three agro-climatic zones (wet, intermediate and dry zones) in Sri Lanka (Table 1). Maize variety "Ruwan" was planted in all sites and managed under the recommended (Technoguide, 1996) management conditions in 2012/13 Maha season.

In all experimental sites, plots were arranged with three replicates. Plots of $5 \mathrm{~m} \times 5 \mathrm{~m}$ were planted with standard crop density (55,000 plants /ha) with inter- and intra-row spacing of 60 $\mathrm{cm} \times 30 \mathrm{~cm}$, respectively. Plots were planted with two seeds per hill and thinned down to one plant per hill to achieve the standard crop density. Sites were kept free from weeds, insect pests, diseases and water stress to achieve potential growth and yield formation. 


\section{Measurements}

At Kundasale, meteorological data, including air temperature $\left({ }^{\circ} \mathrm{C}\right)$, rainfall $(\mathrm{mm})$ and daily irradiance $\left(\mathrm{Wm}^{-2}\right)$, were collected using an on-site "WatchDog 2000" series weather station (Spectrum Technologies, Inc. USA).

Table 1. Meteorological characteristics of experimental sites.

\begin{tabular}{lccccc}
\hline Experimental site & \multicolumn{2}{c}{$\begin{array}{c}\text { Mean Air } \\
\text { Temperature }\left({ }^{\circ} \mathbf{C}\right)\end{array}$} & \multicolumn{2}{c}{$\begin{array}{c}\text { Rainfall } \\
(\mathbf{m m})\end{array}$} & $\begin{array}{c}\text { Mean ET } \\
\left.\text { (mmday }^{-1}\right)\end{array}$ \\
\hline & Season & Annual $^{\mathrm{b}}$ & Season & Annual $^{\text {a }}$ & Season \\
\hline Peradeniya & 25.1 & 25.2 & 716.8 & 2100 & 3.0 \\
Mahailluppallama & 26.9 & 27.6 & 518.6 & 1000 & 3.0 \\
Kundasale & 24.8 & 25.2 & 979 & 1500 & 2.5 \\
\hline
\end{tabular}

Source: ${ }^{a}$ Punyawardana, 2008; ${ }^{b}$ Natural Resource Management Centre, Department of Agriculture, Sri Lanka. Annual mean temperature was calculated using 10 year monthly average maximum and minimum temperatures (Mahailluppallama, Peradeniya and Kundasale from 2000 to 2009).

For other sites, data were collected from meteorological stations at Mahailluppallama and Peradeniya (Table 1). Furthermore, mean Evapotranspiration (ET) and ambient temperature of the season was taken as season mean ET and temperature for each experiment.

Randomly selected four plants were tagged in each replicate and used for non-destructive measurements at two-week intervals. Total numbers of fully expanded and expanding leaves were counted until the last leaf was fully expanded. Leaf length (from ligule to leaf tip) and width (at the widest position of the leaf blade) of the youngest fully expanded leaf was recorded. Furthermore, date of planting, number of days taken to emerge, days to attend $50 \%$ emergence, flowering and maturity were recorded. Dry weights of leaf, stem, roots, tassel, cobs and leaf area were measured by using destructive plant samples (one plant per each replicate) taken at 50\% flowering. Actual leaf area was measured by using a leaf area meter (AAM 9, made by Hayashi Denoko Co.Ltd, Japan). Furthermore, roots, leaf, stem, cob and seed dry weights were measured at crop maturity. Leaf initiation, individual leaf area, LAI, dry matter partitioning measured at Kundasale were used for model development and calibration. Moreover, dry matter partitioning was estimated at 50\% flowering and at physiological maturity by using above mentioned destructive plant samples. Model validation was done using the leaf development, dry matter partitioning, and yield data collected at Peradeniya and Mahailluppalama.

Model was developed in "R" version 2.15. Graphical analyses were done in MS Excel-2007. Goodness of the fit of the model was evaluated through Root Mean Square Error (RMSE) as follows.

$$
\text { RMSE }=\sqrt{\frac{1}{n}} \sum_{1}^{n}(\text { simulated }- \text { observed })^{2} \quad \text { Equation } 1
$$

where, $n$ is the number of observations. Furthermore, model efficiency index (EFI) was calculated by the procedure given in Zadeh et al. (2011). 


\section{Model Development}

Fig. 1 gives an overview of the model which consists of three sub-models (i.e. canopy development, radiation interception, and biomass production and partitioning). Meteorological data were used as driving variables for canopy development and radiation interception sub-models.

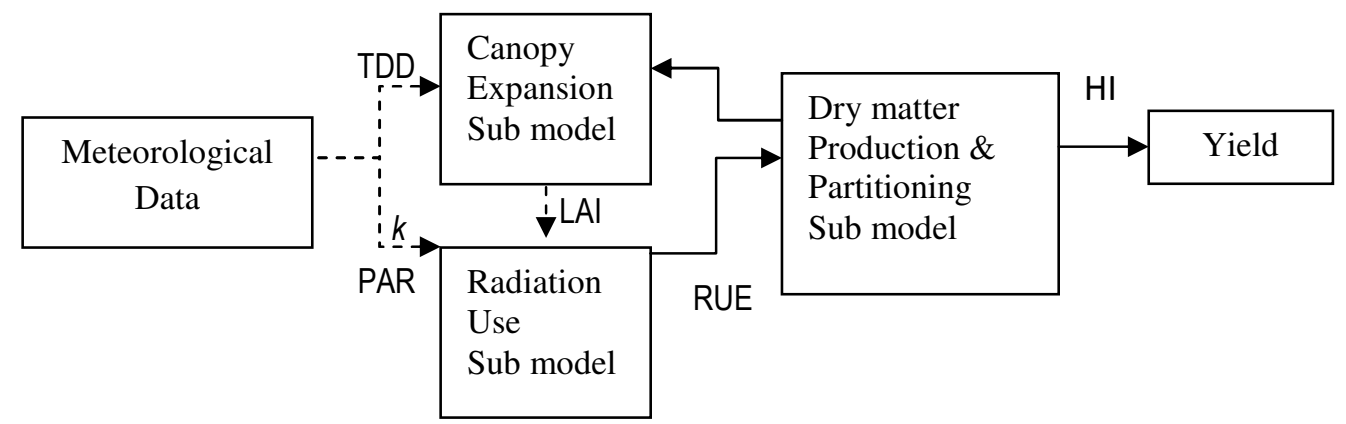

Fig. 1. Schematic overview of the model with information (doted lines) and material (solid lines) flow through the sub models. TDD - Thermal degree days ( ${ }^{\circ} \mathrm{C}$ day); $k$ - canopy light extinction coefficient; PAR - Photosynthetically active radiation (MJ $\mathrm{m}^{-2} \mathrm{~d}^{-1}$ ); LAI - Leaf area index; RUE - Radiation use efficiency $\left(\mathrm{g} \mathrm{MJ}^{-1}\right)$ and HI - Harvest index

The model was developed to run on a daily time step. Canopy development of maize is mainly driven by leaf initiation and leaf expansion. In well-watered maize crops, both processes are controlled by temperature. The response of maize phenology to temperature has been studied extensively, and the results have been incorporated in to crop simulation models (Grant, 1989; Muchow et al., 1990; Kiniry, 1991; Wilson et al., 1995). Canopy development of maize is a multi functional process which includes four processes, namely, leaf emergence, leaf expansion, leaf area duration and leaf senescence (Marcelis et al., 1998; Soltani et al., 2006).

As mentioned earlier, Kundasale, where the meteorological data were available on-site on a continuous basis, was used for model parameterization. Total spectrum solar radiation $\left(\mathrm{Wm}^{-}\right.$ ${ }^{2}$ ) was converted to PAR $\left(\mathrm{MJ} \mathrm{m}^{-2} \mathrm{~d}^{-1}\right)$ by multiplying by 0.5 (assuming a PAR fraction of 0.5 in total solar radiation) and day length (Monteith, 1977). Main determinants of plant biomass production are the interception of radiation by the foliage canopy and radiation-use efficiency (RUE) (Muchow, 1988; Lindquist \& Mortensen, 1999; Bonhomme, 2000). In the absence of water stress, LAI, which is a major determinant of radiation interception, is controlled by the temperature-dependent processes, leaf initiation and expansion. Rates of temperature-dependent developmental processes can be described as a function of thermal time $\left(\mathrm{TDD}_{[\mathrm{n}]}\right)$ as,

$T D D_{n}=\sum_{i=1}^{n} t_{\text {mean }}-t_{b}$

Equation 2

where, $t_{\text {mean }}$ and $t_{b}$ are the daily mean and base temperatures, respectively. Accordingly, cumulative thermal time on the $n^{\text {th }}$ day was calculated by summing $\left(\mathrm{t}_{\text {mean }}-\mathrm{t}_{\mathrm{b}}\right)$ over the period up to day $n$. Daily mean temperature $\left(\mathrm{t}_{\text {mean }}\right)$ was calculated as,

$t_{\text {mean }}=\frac{t_{\min }+t_{\max }}{2}$

Equation 3 
where, $t_{\min }$ and $t_{\max }$ are the daily minimum and maximum temperatures, respectively for a given day. Values ranging from 8 to $10{ }^{\circ} \mathrm{C}$ have been used as $\mathrm{t}_{\mathrm{b}}$ for maize (Ritchie \& Smith, 1991; 2005; Lukeba et al., 2013) in simulation models. However, based on literature and widespread crop models, $\mathrm{t}_{\mathrm{b}}$ value of $8{ }^{\circ} \mathrm{C}$ was used in the present model.

\section{Leaf Initiation and Plant Architecture}

Area of a fully expanded leaf $\left(L A_{n}\right)$, on the $\mathrm{n}^{\text {th }}$ leaf position from the base was achieved when the length $\left(L_{n}\right)$ and width $\left(W_{n}\right)$ reached a leaf position-specific maximum. The function described by Lizaso et al. (2003) was used to quantify the maximum area per leaf in the $\mathrm{n}^{\text {th }}$ leaf position as,

$$
\begin{array}{ll}
L A_{n}=\beta \times L_{n} \times W_{n} & \text { Equation } 4
\end{array}
$$

Leaf length and width data obtained from Kundasale field experiment were regressed to estimate the parameter $\beta$. Moreover, canopy expansion data (i.e. number of fully expanded leaves added) collected from four tagged plants were regressed to develop the relationship between number of leaves added to canopy and thermal time (Fig. 3). Hence, model to calculate the number of fully expanded leaves based on the cumulative thermal time as

$$
L_{n}=2.127 e^{\left(2 \times 10^{-3} \times T D D\right)}
$$

Equation 5

where, $L_{n}$ is the number of fully expanded leaves (Fig. 3). Based on the observed data (data not shown) $50 \%$ of emergency was completed at $75^{\circ} \mathrm{C}$ days. Therefore, canopy growth sub model simulate the opening of fully expanded leaves after emergency. Furthermore, time taken for seedling emergence was taken as the time gap between the date of sowing to first leaf opening. Leaves were initiated at regular intervals of thermal time. Area per leaf at different leaf positions were estimated by using the model developed by Keating \& Wafula (1992).

$$
L A_{n}=Y_{0} e^{a\left(x_{n}-x_{0}\right)^{2}+b\left(x_{n}-x_{0}\right)^{a}}
$$

Equation 6

$L A_{n}$ is the area of a leaf appearing in the $n^{\text {th }}$ leaf position. Potential leaf area $\left(Y_{0}\right)$ of $n^{\text {th }}$ leaf position was achieved by using equation 4 based on the field data. Site specific parameters are given as ' $a$ ' and ' $b$ '. Potential leaf number $\left(X_{n}\right)$ was the encountered maximum number of leaves (i.e. 22) by the selected variety and $X_{0}$ is the leaf position (i.e. 1-22). Furthermore, Equation 6 underestimated the area per leaf of the first six leaf positions. Therefore, based on the experimental data a polynomial function was fitted to simulate the area of leaves below the $7^{\text {th }}$ leaf position (eq. 06).

$$
L A_{n}=1.687(T D D)^{2}+0.64(T D D)-1.578 \quad \text { Equation } 7
$$

Therfore, area of an individulal leaf was simulated as a function of thermal time and leaf position (i.e. eq. 6 and 7). 


\section{Leaf Senescence}

Terminal phase of plant development in a given organ (e.g. including leaves, stems, flowers and fruits) or a whole plant, is known as senescence (Dangl et al., 2000). Leaf senescence pattern in maize has been studied extensively and generally begins after $400-450{ }^{\circ} \mathrm{C}$ day (Borrás et al., 2003). Leaf senescence is influenced by various environmental (e.g. temperature and water stress) and internal factors (e.g. hormonal balance). Furthermore, it does include initiation, degeneration, and terminal phases (Nooden et al., 1997). However, in the field it is possible to identify the terminal phase as it is characterized by yellowing of laminas. Therefore, a leaf was considered as senesced when more than half of its area became yellow. Accordingly the senesced leaf area (LAS) of a plant could be simulated using the function;

$$
L A S=4 \times 10^{-7}(T D D)^{3.047}
$$

Equation 8

Leaf area senescence (LAS) is a function of thermal time which occurs slowly in the initial phase which is followed by a rapid decaying towards crop maturity. Therefore, the model simulated a decline in LAI at crop maturity. Therefore, the active leaf area was simulated as a balance between the sum of expanded and expanding leaf area, and the area of senesced leaves.

\section{Light Interception}

The model simulates light interception $\left(I_{i}\right)$ as a function of active LAI and light extinction coefficient $(k)$. Light extinction coefficient depends on environment conditions, solar elevation angle, growth stage of the crop, and plant characteristics such as leaf angle and LAI (Tohidi et al., 2012). Based on literature $k$ value for maize was considered as 0.4 (Gallo \& Daughrty, 1986). Therefore, $I_{i}$ was simulated as follows,

$$
\begin{array}{ll}
I_{i}=1-I_{0} e^{(-k \times L A I)} & \text { Equation } 9
\end{array}
$$

\section{Dry Matter Accumulation and Yield}

Plant dry matter accumulation depends on the fraction of carbon converted to dry matter during the photosynthesis process. In the absence of stresses, plant dry matter accumulation depends on the quantity of radiation absorbed by the canopy (Monteith, 1977; Sinclair \& Muchow, 1999). Therefore, the model simulates biomass production as a function of $l_{i}$ and RUE. Loomis \& Amthor (1999) estimated the potential RUE for maize as $4.9 \mathrm{~g}$ of total biomass per unit intercepted PAR $\left(\mathrm{g} \mathrm{MJ}^{-1}\right)$. Therefore, model simulates the biomass production by using RUE as $4.9 \mathrm{~g} \mathrm{MJ}^{-1}$. Based on dry matter accumulation and $\mathrm{HI}(0.4)$, the model simulated the final yield.

\section{RESULTS AND DISCUSSION}

As mentioned in the methodology individual leaf area was estimated by the relationship developed by Lizaso et al. (2003). The observed data from Kundasale were regressed to estimate parameter $\beta(0.753)$ (eq. 4$)$ using a simple linear regression $\left(R^{2}=0.98\right)$. The leaf area model was validated using data collected at Peradeniya (Fig. 2). 


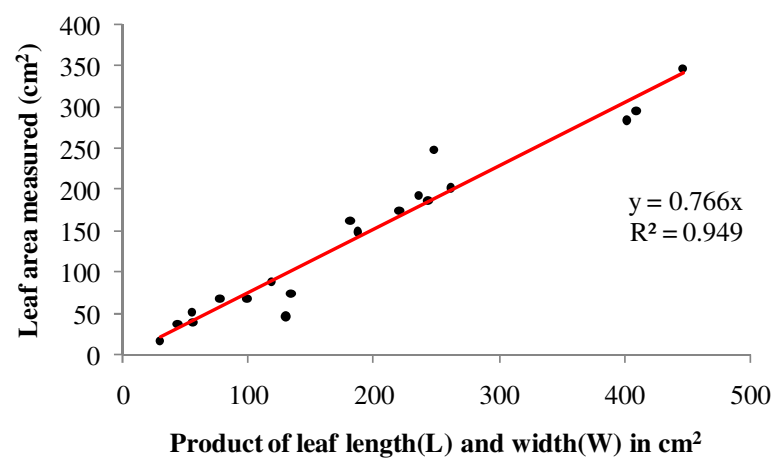

Fig. 2. Relationship between estimated and measured leaf area. Leaf are estimation was done by using equation 04 by using field observed data from Peradeniya. $R M S E$ and EFI were 22.08 and 0.053 respectively.

\section{Leaf Initiation and Individual Leaf Area}

Rate of adding new expanded leaves to the canopy was less during the initial growth stage and increased exponentially as thermal time progressed until it produced the ear leaf. Simulated and observed expanded leaves (data obtained from four tagged plants of each replicate) with thermal time are given in Fig. 3.

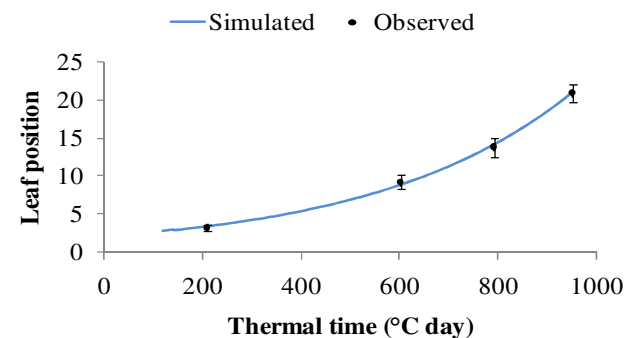

a

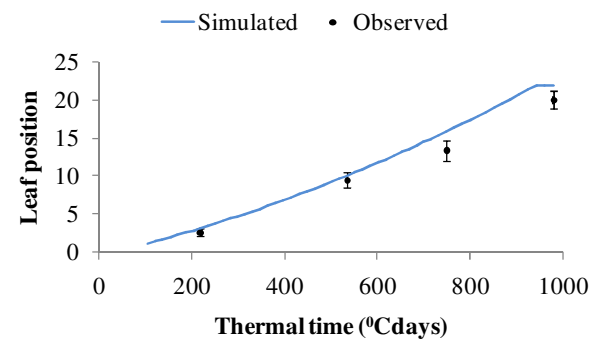

b

Fig. 3. Simulated and observed leaf initiation in maize as a response to thermal time. Simulations were based on equations 5 and the observed leaf initiation data are from Kundasale(a) and Peradeniya(b). Mean RMSE and EFI value are 0.89, $1.6,-0.13$ and $\mathbf{- 0 . 9 4}$ respectively

The first six leaves were relatively small and occurred in short internodes. Furthermore, longevity (i.e. lifespan) of these leaves were also short and most of them senesced before tasseling (data not shown). However, this was followed by leaves with higher area per leaf (i.e. 7-16 leaf positions). Beyond the $16^{\text {th }}$ leaf position, the area of a single leaf decreased. The final leaf position produced a comparatively smaller ear leaf. Moreover, individual leaf area reached a maximum at 15-17 leaf position and gradually decreased towards the ear leaf. Therefore, individual leaf area along the leaf position could be explained as a typical bell shape curve. 


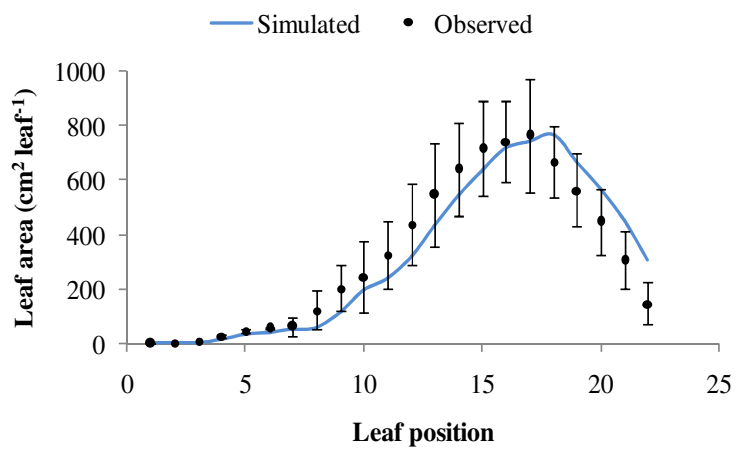

Fig. 4. Leaf area of individual leaves of maize as a response to the leaf position. Area per leaf was calculated based on equations 4-6. The error bars are derived from the Kundasale data and mean RMSE and EFI values were 81.13 and 0.9 respectively

As mentioned in the section on model development, total LAI is the summation of expanded and expanding leaf area. However, active LAI is the balance between expanding, expanded and senesced leaf area (i.e. eq. 4, 6 and 7). Therefore, simulated active LAI (green leaf area) was compared with observed LAI.

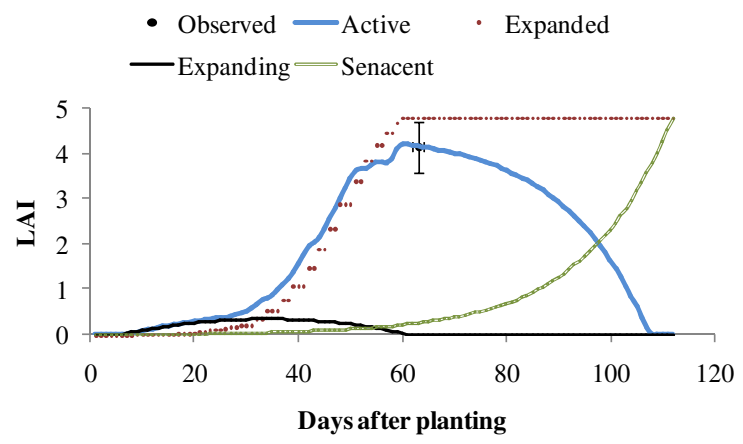

Fig. 5. Observed and simulated active LAI based on expanded, expanding and senesced leaf area index at Kundasale. Calculated RMSE and EFI values are 0.45 and $\mathbf{- 0 . 7 2}$ respectively

Expanding leaf area made the highest contribution to the active LAI during the early plant growth (up to 30-35 days after planting (DAP)). Beyond 30-35 DAP, the proportional contribution of expanding leaf area was less and the increase of active LAI was more dependent on the expanded leaf area. Model simulated maximum active leaf area index (44.5) was reached at 50 to $60 \mathrm{DAP}$ and gradually decreased thereafter due to leaf senescence. However, sharp reduction of active LAI occurs after 90 DAP. During early stages (i.e. before silking) leaf senescence occurred from bottom to ear leaf. However, rapid LAS at maturity was due to two-way decaying of leaves from bottom to top, and top to bottom directions. A similar observation was made by Tsimba et al. (2013). 


\section{Light Interception}

In the present study, maximum light interception, was achieved when LAI reached 4 (8471387 degree days), and a similar observation was made by Maddonni \& Otegui (1996). Conversely, models proposed in the literature estimate the maximum light interception of maize at a LAI of 5 (Muchow et al., 1990; Gallo et al., 1993). Simulated LAI at Peradeniya reached the maximum at 959 to 1161 degree days, Mahailluppalama it is 873 to 1387 degree days decreased thereafter (Fig. 6).

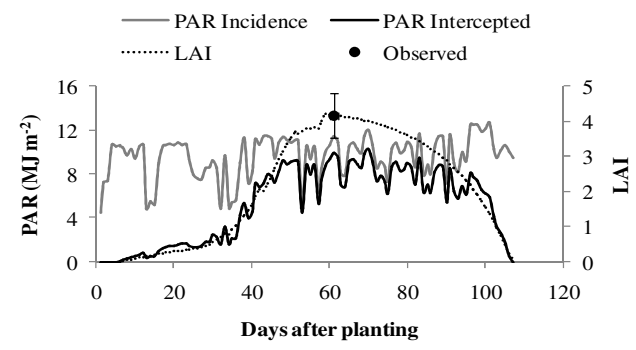

a

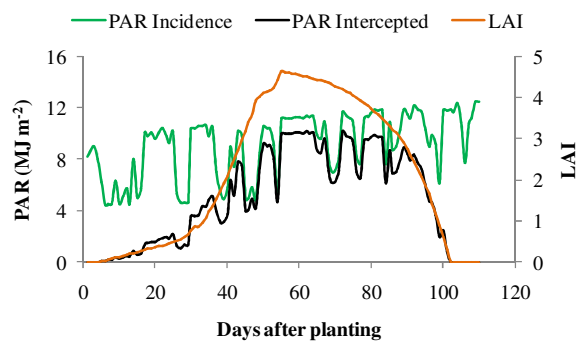

b

Fig. 6. Simulated light interception and LAI (a) Peradeniya (b) Mahailluppallama. Calculated RMSE and EF value for LAI Peradeniya were 0.028 and $-5.19 \times 10^{-6}$ respectively.

Time taken to reach maximum LAI was shorter at Mahailluppalama (55 DAP) compared with that at Peradeniya (58 DAP) and Kundasale (60 DAP) corresponding to cumulative thermal times of 968,959 and 930 degree days, respectively. Therefore, it could be concluded that the variety 'Ruwan' of Maize requires on average a thermal duration of 952 degree days to reach maximum LAI in the absence of water stress. The faster developmental rate at Mahailluppalama was due to higher mean seasonal temperature (Table 01). Moreover, the number of days taken to reach crop maturity was lower at Mahailluppalama than at the other two sites, i.e. the simulated values of crop maturity for two sites were 102 DAP (1895 degree days) at Mahailluppalama, 107 DAP (1866 degree days) at Peradeniya and field observed actual values were 103 DAP and 111 DAP, respectively. Therefore, mean thermal duration required for crop maturity of variety Ruwan is around 1879 degree days.

\section{Above Ground Biomass and Yield}

Model prediction was compared with the filed observed data at Mahailluppallama and Peradeniya at tasseling and crop maturity. 


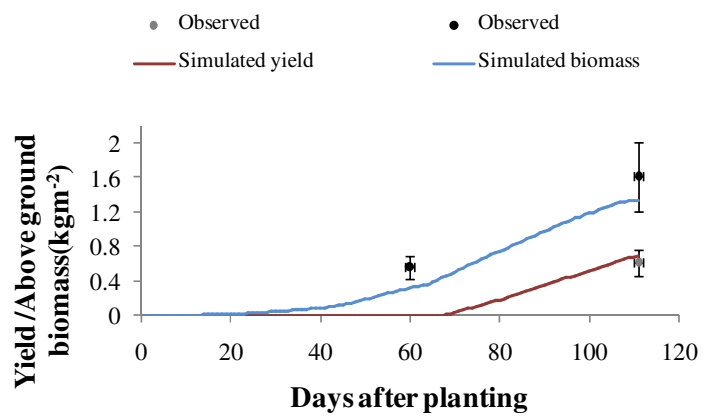

Fig. 7. Simulated and observed above ground dry matter (black line and symbols) accumulation and yield (gray line and symbol) at Kundasale. Respective RMSE and EFI values are $0.37,0.14,-0.8$ and -0.3 respectively

Dry matter partitioning between root and shoot were $0.15 \pm 0.03$ and $0.85 \pm 0.02$, respectively at $50 \%$ flowering, and $0.11 \pm 0.03$ and $0.89 \pm 0.06$ at maturity. Therefore, partitioning at $50 \%$ flowering and maturity were similar. Hence, the model simulates 0.15 of dry matter portioning to roots as a proportion of the biomass produced in a day.
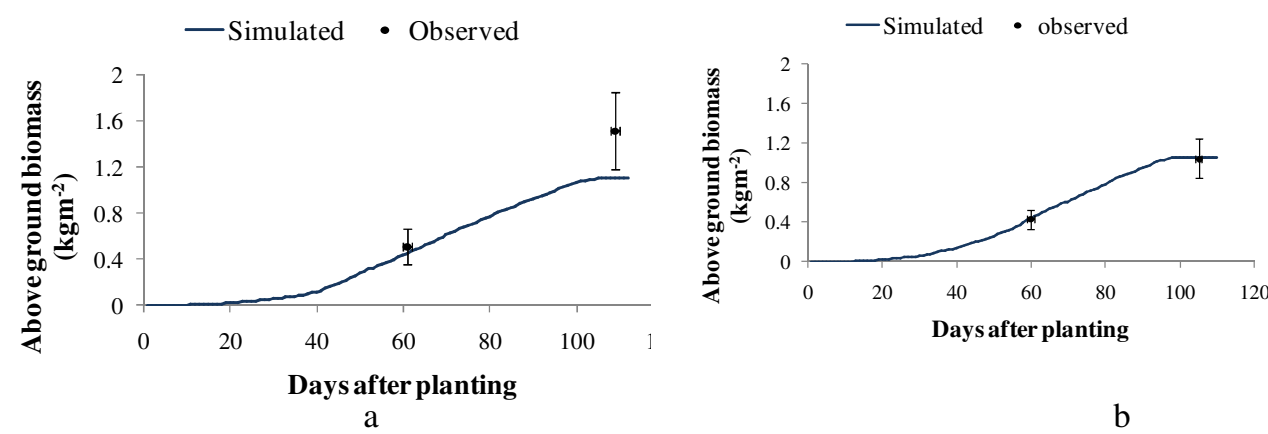

a

b

Fig. 8. Simulated and observed above ground biomass accumulation at Peradeniya (a) Mahailluppallama (b) Respective mean RMSE and EFI values are 0.31, 0.14, 1.2and-0.004

Simulated above ground biomass at tasseling and crop maturity had a close fit at Mahailluppallama and Peradeniya (Fig. 8).

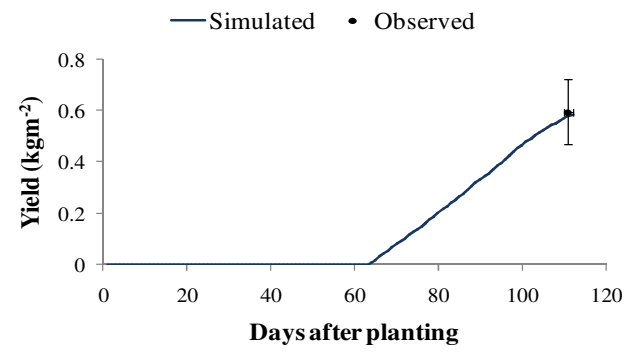

a

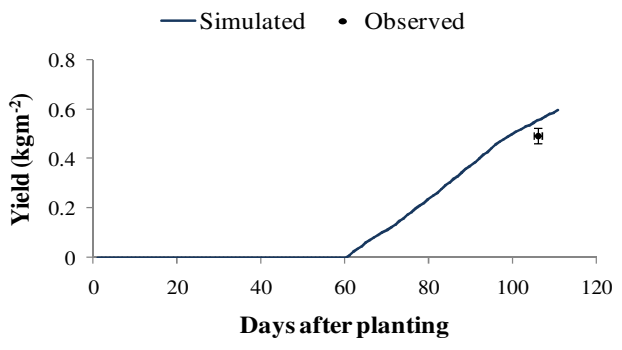

b

Fig. 9. Simulated and observed yield at Peradeniya (a) and Mahailluppallama (b) and RMSE and EF values for the respective sites are $0.009,0.04,-0.03$ and -5.25 
Simulated agronomic yield of maize also closly fitted with the observed data in two locations (Fig. 9). Grain filling commenced from 60 and 65 DAP at Mahailluppallama (1055 degree days) and Peradefniya (1089 degree days) respectively. Grain yield at Mahailluppallama $\left(0.49 \mathrm{~kg} \mathrm{~m}^{-2}\right)$ was lower than at Peradeniya $\left(0.57 \mathrm{~kg} \mathrm{~m}^{-2}\right)$. Moreover, higest yield was achived in Kundasale $\left(0.61 \mathrm{~kg} \mathrm{~m}^{-2}\right)$ which had the longest crop duration. Therefore, lesser yield of Mahailluppallama could be attributed to the shorter crop duration (Fig. 10).

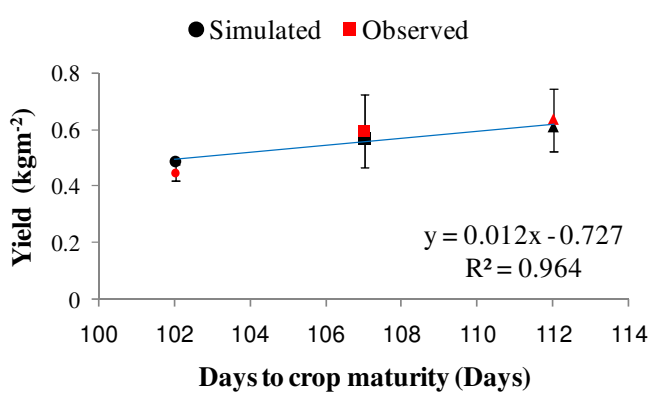

a

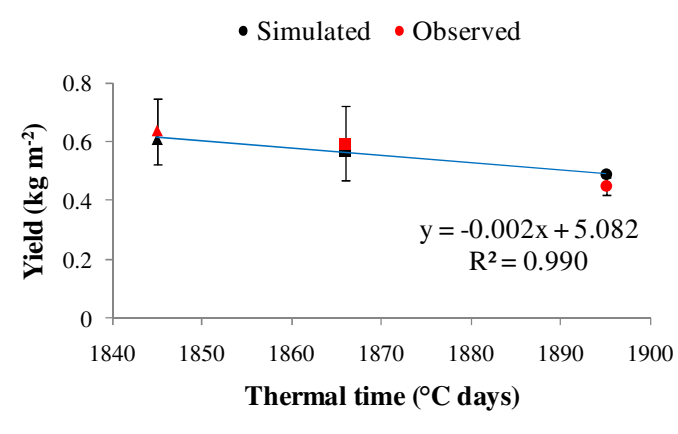

$\mathrm{b}$

Fig. 10. Relationship between (a) yield and days to maturity, and (b) yield and thermal time considering both simulated (black colour symbols) and observed yields (grey colour symbols) at Mahailluppallama (circle) Peradeniya (squire) and Kundasale (triangle). Average RMSE and EFI were 0.032 and -1.5 respectively.

Rate of yield increment per unit day extend of crop is $0.012 \mathrm{~kg} \mathrm{~m}^{-2}$ (Fig. 10 (a)) beyond 102 DAP. Furthermore, yield shows decresing trend at a rate of $0.002 \mathrm{~kg} \mathrm{~m}^{-2}$ per unit increse of thermal time after 1840 degree days (Fig. 10(b)). Moreover, total PAR intercepted by the crop are 534.5, 555.6 and 816.1 $\mathrm{MJ} \mathrm{m}^{-2}$ in Mahailluppalama, Peradeniya and Kundasale respectively. Therfore, yield reduction at higher mean seasonal temperature could be explained as functions of crop duration and intercepted PAR.

\section{Concluding remarks}

The present version of the model focuses mainly on a detailed quantification of leaf initiation and expansion of maize. This enabled prediction of the time course of LAI variation of maize growing under recommended crop management practices. Close agreement between predicted and observed values of LAI, biomass accumulation and yield demonstrate the present version of the model is simulating the canopy development of maize under recommended crop management satisfactorily. Further improvement in the model is in progress to enable it to predict the growth and yield formation of maize under different crop management practices in a wide range of agro-ecological regions in Sri Lanka.

\section{ACKNOWLEDGEMENT}

Authers express their gratitude to HETC-QIG-W3-PGIA project for the finacial support and also to University of Peradeniya, Department of Agriculture and their staff for providing required facilities to conduct field experiments. 


\section{REFERENCE}

Birch, C.J., Hammer, G.L., and Rickert, K.G. (1998). Improved methods for predicting individual leaf area and leaf senescence in maize (Zea mays). Aust. J. Agri. Rese. 49(02), 249-262.

Bonhomme, R. (2000). Beware of comparing RUE values calculated from PAR vs. solar radiation or absorbed vs. intercepted radiation. Fiel. Crop. Rese. 68, 247-252.

Borras, L., Maddonni, G.A. and Otegui, M.E. (2003). Leaf senescence in maize hybrids: plant population, row spacing and kernel set effects. Fiel. Crop. Rese. 82(1), 13-26.

Dangl, J.L., Dietrich, R.A. and Thomas, T. (2000). Senescence and programmed cell death. pp. 1044-1100 In: Buchanan B., Gruissem W. and Jones R. (Ed), Biochemistry and molecular biology of plants.

Dwyer, L.M. and Stewart, D.W. (1986). Leaf area development in field grown maize. Agro. J. 78(02), 334-343.

Gallo, K.P. and Daughrty, C.S.T. (1986). Techniques for measureing intercepted and absorbed photosynthetically active radiation in corn canopies. Agro. J. 78, 752-756.

Grant, R.F. (1989). Simulation of maize phenology. Agro. J. 81, 451-457.

Jones, J.W., Hoogenboom, G., Porter, C.H., Boote, K.J., Batchelor, W.D., Hunt, L.A., Wilkens, P.W., Singh, U., Gijsman, A.J. and Ritchie, J.T. (2003). The DSSAT cropping system model. Euro. J. Agro. 18, 235-265.

Keating, B.A. and B.M. Wafula, B.M. (1992). Modeling the fully expanded area of maize leaves. Fiel. Crop. Rese. 29(2), 163-176.

Kiniry, J.R. (1991). Maize phasic development. pp. 55-70. In: Hanks, R.T. and Ritchie, J.T. (Ed.), Modeling Plant and Soil Systems. Amer. Soci. Agro. Mono. 31.

Lindquist, J.L. and Mortensen, D.A. (1999). Ecophysiological characteristics of four maize hybrids and Abutilon theophrasti. Weed. Rese. 39, 271-285.

Lizaso, J.I., Batchelor, W.D. and Westgate' M.E. (2003). A leaf area model to simulate cultivar-specific expansion and senescence of maize leaves. Fiel. Crop. Rese. 8, 1-17.

Loomis, R.S., and Amthor, J.S. (1999). Yield potential, plant assimilatory capacity, and metabolic efficiencies. Cro. Scie. 39, 1584-1596.

Lukeba, J.C.L., Vumilia, R.K., Nkongolo, K.C.K., Mwabila, M.L. and Tsumbu, M. (2013). Growth and leaf area index simulation in maize (Zea mays L.) under small-scale farm conditions in a sub-saharan african region. Amer. J. Plan. Scie. 4, 575-583.

Mallaviarachchi, M.A.P.W.K., Lesly, W.D., Jayawardane, S.N. and Ethakade D.M.G. (2008). Potential of maize (Zea mays) and chilli (Capsicum annum) intercropping under supplementary irrigation. Annals of the Sri Lanka department of agriculture. 10, 97-104. 
Marcelis, L.F.M., Heuvelink, E. and Goudriaan, J. (1998). Modelling biomass production and yield of horticultural crops: a review. Sci. Hort.. 74, 83-111.

Monteith, J.L. (1977). Climate and the efficiency of crop production in Britain. Philos. Trans. R. Soc. London, Ser. B. 281, 277-294.

Muchow, R.C. (1989) Comparative productivity of maize, sorghum and pearl millet in a semi-arid tropical environment: I. Yield potential. Fiel. Crop. Res. 20, 191-205.

Muchow, R.C. and Carberry, P.S., (1989) Environmental control of phenology and leaf growth in a tropically adapted maize. Fiel. Crop. Res. 20(3), 221-236.

Muchow, R.C., and R. Davis. (1988) Effect of nitrogen supply on the comparative productivity of maize and sorghum in a semi-arid tropical environment: II. Radiation interception and biomass accumulation. Fiel. Crop. Res. 18, 17-30.

Muchow, R.C., Sinclair, T.R. and Bennett, J.M. (1990). Temperature and solar radiation effects on potential maize yield across locations. Agron. J. 82, 338-343.

Nooden, L.D., Guiamet, J.J. and John, I. (1997). Senescence mechanisms. Phy. Plan.101, 746-753.

Punyawardana, B.V.R. (2008). Agroclimatological zones and rainfall pattern in Sri Lanka (in Sinhala medium). Published by Department of Agriculture, Sri Lanka. 44-91.

Ritchie, J.T. and NeSmith, D.S. (1991). Temperature and crop development. pp. 5-29. In: Hanks, R.J. and Ritchie, J.T. (Ed.). Modeling plant and soil systems. Amer. Soc. Agro. Mono. 31. Madison.

Sangakkara, R., Bandaranayake, S., Attanayake, U. and Stamp, P. (2011). Impact of associated intercrops on growth and yield of maize (Zea mays L) in major seasons of south Asia. Short Communication. Accessed on 24.10.2012. Available at http://www.maydica.org/articles/57_006.pdf.

Setiyono, T.D., Weiss, A., Spcht, J., Bastidas, A.M., Cassman, K.G. and Dobermann, A. (2007). Understanding and modeling the effect of temperature and day length on soy-bean phenology under high yield conditions. Fiel. Crop. Res. 100(2), 257-271.

Sinclair, T.R. and Muchow, R.C. (1999). Radiation use efficiency. Adv. Agron. 65, 215-265.

Soltani, A., Robertson, M.J., Rahemi-Karizaki, A., Poorreza, J. and Zarei, H. (2006). Modelling Biomass Accumulation and Partitioning in Chickpea (Cicer arietinum L.). Agron. Crop. Sci. 192, 379-389.

Technoguid. (1996). Crop recommendation. Department of Agriculture, Sri Lanka.

Timsina, J., Jat, M.L. and Majumdar, K. (2010). Rice maize systems of South Asia: Current status, future prospects and research priorities for nutrient management. Plan. Soil. 335, 6582. 
Tohidi, M., Nadery, A., Siadat, S. and Lak, S. (2012). Variables Productivity of Light Interception in Grain Maize Hybrids at Various Amount of Nitrogen. Worl. Appl. Sci. J. 16(1), 86-93.

Wilson, D.R., Muchow, R.C. and Murgatroyd, C.J. (1995). Model analysis of temperature and solar radiation limitations to maize potential productivity in a cool climate. Fiel. Crop. Res. 43, 1-18.

Zadeh. H.G., Lorzadeh, S. and Ariannia, N.(2011) Validation of model relating crop yield and weed time of emergence and removal. Asia. J. Crop Sci. 3(2), 99-1025. 